\title{
The serial position function for lists learned by a narrative-story mnemonic*
}

\author{
D. J. HERRMANN†, F. V. GEISLER \\ and R. C. ATKINSON \\ Stanford University, Stanford, Calif. 94305
}

In a free recall task when recall is delayed after input, the serial position function exhibits higher performance in the initial positions and depressed performance in the final positions relative to the middle positions. The nature of a S's learning strategy in free recall has been a matter of speculation. The present study examined delayed recall for a learning strategy involving the construction of a story around list items. The delayed serial position function under these conditions differed from the standard paradigm in displaying an elevated performance over the final positions. To the extent that Ss use a story as a mnemonic in a free recall task, delayed performance on the final inputted items should be enhanced.

Findings for immediate recall in a free recall task show greater recall for initial and final inputted items, the familiar positive primacy and recency phenomena. In contrast, delayed recall exhibits the phenomenon of negative recency, initially reported by Craik (1970) and confirmed in several subsequent studies (Rundus \& Atkinson, 1970; McCabe \& Madigan, 1971; Darley \& Murdock, 1971). These studies found that the positive recency effect apparent in immediate free recall disappeared with delayed recall and that performance over the last serial positions was poorer than that for the initial and middle positions.

The strategy used by Ss in many free recall studies is difficult to ascertain. Ss sometimes report constructing stories around the word list they are required to remember. A study by Bower \& Clark (1969) investigated the narrative story as a mnemonic aid and confirmed its value. Bower and Clark instructed one group of Ss to construct a narrative story around a word list, and gave a control group an equal amount of time to study the same list. Final recall was $93 \%$ vs $13 \%$ for narrative vs control groups. Bower and Clark, however, did not report serial position data, probably because the high level of recall for the narrative group precluded observation of differences over serial positions. The present research examined the serial position function for delayed recall of lists learned by the narrative-story strategy. Of primary interest is whether or not the negative recency phenomenon typically found in delayed recall will be found under the special conditions of the narrative-story strategy.

*This research was supported by a SSRC Research Training Fellowship to the second author and a grant from the National Institute of Mental Health (MH 21747) to the third author.

tRequests for reprints should be sent to D. J. Herrmann, Department of Psychology, Hamilton College, Clinton, N.Y. 13323.

\begin{abstract}
METHOD
Subjects

Ss were 32 female Stanford students, who volunteered to participate in an experiment on "creative story telling." Ss were paid $\$ 4$ each and were run in pairs.
\end{abstract}

\section{Stimulus Materials}

Seventeen lists of words were constructed for tne experiment, 1 for the $\mathrm{E}$ to use in instructions and 16 for the Ss to use. Eight lists contained 8 nouns, 8 lists contained 16 nouns, and the E's instructions list contained 5 nouns. Each list was typed in a column on a separate sheet of paper. The words ranged in frequency from 10 to 40 per million words of text in The Teacher's Work Book of 30,000 Words by Thorndike and Lorge. Half of the Ss observed the lists in one order and half observed the lists in the reverse order.

Recognition-test materials consisted of eight pages of 48 words each. On each page, half of the words were targets and half were distractors. Distractors were also drawn from the same frequency range in the Thorndike and Lorge count. There were two sets of recognition-test materials, one for the first eight $S$ pairs and one for the second eight $S$ pairs.

\section{Procedure}

The Ss were told initially that the purpose of the experiment was to investigate creative storytelling. Thus, the effects of the narrative mnemonic were studied free of intention to learn. Ss were instructed to glance over the list and then to create a story aloud from the list, using the words in serial order and creating one sentence for each word. The Ss alternated in the role of storyteller and listener, i.e., while one $\mathrm{S}$ told a story, the other $\mathrm{S}$ listened to the story. To insure that the listener paid attention to the story, she was required to rate the story on the story's interest value and on the story's cohesiveness. Each $S$ constructed four stories from the 8-item lists and four from the 16-item lists.

After stories had been generated for all the lists, each S attempted a written recall of the words from all the lists in a period of $12 \mathrm{~min}$. After completion of the recall task, Ss were given the recognition sheets. Ss were directed to circle 24 of the 48 words on each sheet. Ss were given as much time as needed for the recognition task.

\section{RESULTS}

Table 1 presents the mean percentage of words recalled and recognized for 8- and 16-item lists as a function of whether the $\mathrm{S}$ had acted as storyteller or listener for particular stories. Examination of the table shows clear differences between storyteller and listener in every case. Analysis of variance showed that performance was consistently higher for the storyteller than for the listener, $p<.01$ for recall and recognition of 8- and 16-item lists. The table also shows that percent correct recall was higher for 8 -item lists $(39 \%)$ than for 16 -item lists $(34 \%)$, but that recognition accuracy was essentially equal for 8-and 16-item lists (85\%).

As would be expected, Ss made intrusions in their recall. The intrusions were few in number, an average 2.1 words out of an average 68.1 words recalled, an intrusion rate comparable to the standard free recall task. The range in intrusions was small, from zero to six 
Table 1

Percent Correct Recall and Recognition of 8- and 16-Item Lists as a Function of Subjects' Role as Storyteller and Listener

\begin{tabular}{|c|c|c|c|c|}
\hline & \multicolumn{2}{|c|}{8 Items } & \multicolumn{2}{|c|}{16 Items } \\
\hline & Story tel & Listener & Story te & Listener \\
\hline $\begin{array}{l}\text { Recall } \\
\text { Recognition }\end{array}$ & $\begin{array}{l}54 \\
91\end{array}$ & $\begin{array}{l}23 \\
79\end{array}$ & $\begin{array}{l}47 \\
89\end{array}$ & $\begin{array}{l}21 \\
79\end{array}$ \\
\hline
\end{tabular}

items per S. It is interesting to note that nearly all of the intrusions were from other words which Ss used in their stories.

The serial position functions for delayed recall and recognition are shown in Fig. 1. The functions for 8 - and 16-item lists have been averaged over conditions of storyteller and listener, since the shape of the curve was the same for these conditions. Examination of the figure shows that in recall there was improved performance at the first and last portions of the list. Analysis of variance of recall scores showed that the serial position effect for 8- and 16-item lists was significant: for 8-item lists, $F(7,21.7)=2.14, p<.01$, and for 16 -item lists, $F(15,465)=3.72, p<.01$. Analysis of variance for recognition scores shows a significant serial position effect for 8-item lists but not for 16-item lists: for

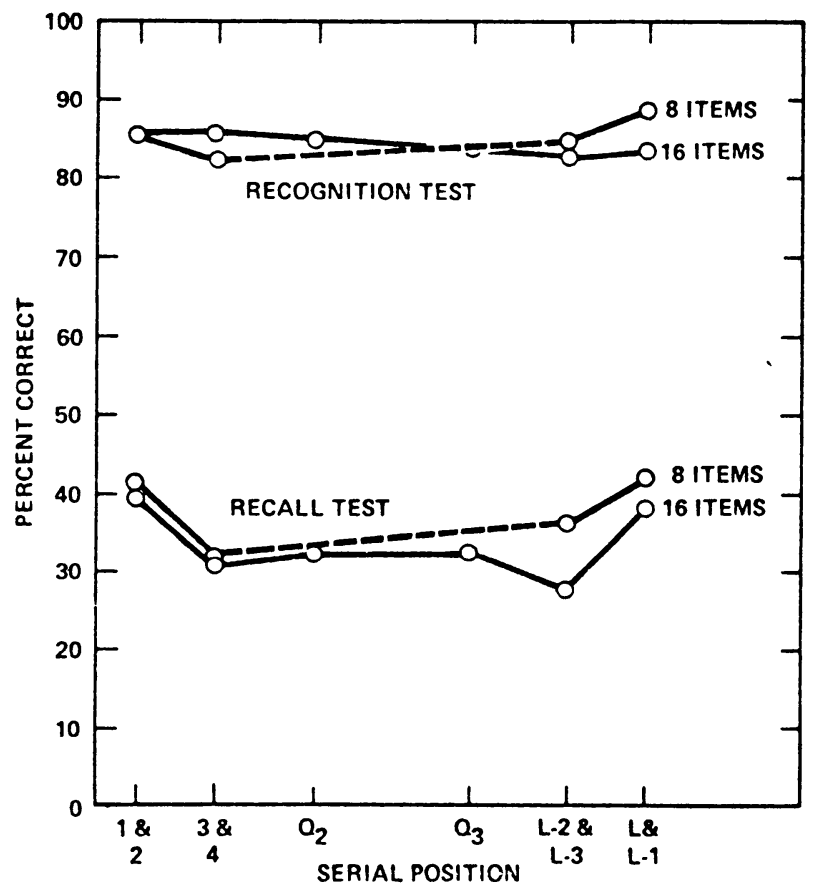

Fig. 1. Percent correct recall and recognition for 8- and 16-item lists as a function of the serial position of list items. $L$, L-1, L-2, and L-3 refer to Serial Positions 16, 15, 14, and 13 for the 16-item list, and to Positions 8,7,6, and 5 for the 8-item list. The $Q_{2}$ and $Q_{3}$ are second and third quartile positions for the 16-item list (i.e., $Q_{2}$ is the average over Positions 5-8 and $Q_{3}$ is the average for Positions 9-12 for the 16-item list). 8-item lists, $F(7.217)=3.05 . p<.01$, and for 16 -item lists, $F(15,465)=1.22, p>.05$.

\section{DISCUSSION}

If the delayed recall in the present study had behaved like that in the typical free recall experiment, then a curve with positive primacy but negative recency would have been observed. However, while the positive primacy effect still was evident, the curve displayed positive rather than negative recency. Thus, it is concluded that, to the extent a narrative-story mnemonic is used in the free recall task, a positive recency will result.

The curve obtained in the present study possessed a bowed shape similar to that found in immediate free recall. In the case of immediate recall, primacy is presumably due to greater rehearsal of the first few words and positive recency is due to the close proximity of rehearsal and the recall task in time, i.e., the retrieval of items from short-term memory (Atkinson \& Shiffrin, 1971). Do these explanations apply to the effects of the narrative mnemonic as well? The added rehearsal explanation of primacy seems to remain applicable. The recency portion of the curve's being due to short-term memory, however, can be ruled out. The average delay between construction of a story and recall was $30 \mathrm{~min}$. With this long a period between construction and recall, output of the words from short-term memory cannot account for the recency effect.

A plausible explanation of the present serial position function is that the beginning and end portions of the story serve as anchors to its recall, and thus are remembered better. The $S$ was instructed to attempt to construct cohesive stories. In her attempt to do so, she had to tie the different parts of the story together. The first few words of the list were used to develop the story's theme, and the last few words of the list were used to form a cohesive conclusion to her story. Introspective data and inspection of recall protocols indicated that when presented with the recall task, the Ss first attempt to recall the theme of the story. Recall of the theme cues recall of the sentences and of the list words contained in the sentences. Since the beginning and end words are tied most closely to the theme, recall is higher at each end of the list.

The serial position function found for recall of 8-and 16-item lists was also found for the 8-item list in recognition. Why no differences in serial position were found in recognition of the 16 -item lists is not clear. It is also interesting to note that recall accuracy decreased as list length increased, while recognition accuracy was not affected by list length. It may be that list length has its effect on retrieval as opposed to storage processes.

\section{REFERENCES}

Atkinson, R. C., \& Shiffrin, R. M. The control of short term memory. Scientific American, 1971, 225, 82-90.

Bower, G. H. \& Clark, M. C. Narrative stories as mediators for serial learning. Psychonomic Science, 1969, 14, 181-182.

Craik, F. I. M. The fate of primary memory items in free recall. Journal of Verbal Learning \& Verbal Behavior, 1970, 9, 143-148.

Darley, C. F., \& Muroiock, B. B., Jr. Effects of prior free recall testing on final recall and recognition. Journal of Experimental Psychology, 1971, 91, 66-73.

McCabe, L., \& Madigan, S. A. Negative effects of recency in recall and recognition. Journal of Verbal Learning \& Verbal Behavior, 1971, 10, 307-310.

Rundus, D., \& Atkinson, R. C. Rehearsal process in free recall: A procedure for direct observation. Journal of Verbal Learning \& Verbal Behavior, 1970, 9, 99-105.

(Received for publication August 24, 1973.) 